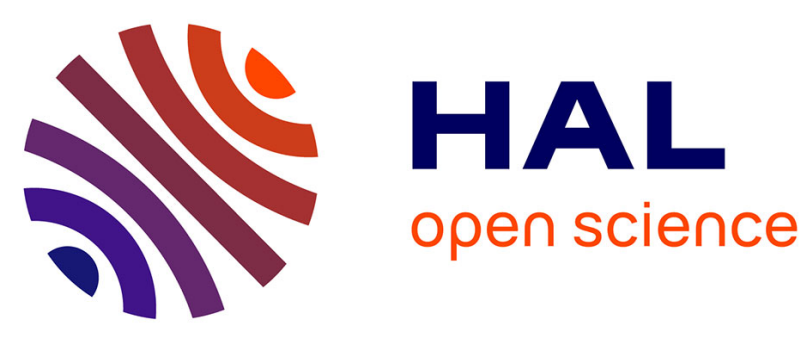

\title{
Bis-Thioether-Containing Lipid Chains in Cationic Amphiphiles: Physicochemical Properties and Applications in Gene Delivery
}

Amal Bouraoui, Rosy Ghanem, Mathieu Berchel, Véronique Vié, Yann Le Guen, Gilles Paboeuf, Laure Burel-Deschamps, Tony Le Gall, Tristan Montier, Paul-Alain Jaffres

\section{To cite this version:}

Amal Bouraoui, Rosy Ghanem, Mathieu Berchel, Véronique Vié, Yann Le Guen, et al.. Bis-ThioetherContaining Lipid Chains in Cationic Amphiphiles: Physicochemical Properties and Applications in Gene Delivery. ChemPhysChem, 2019, 20 (17), pp.2187-2194. 10.1002/cphc.201900626 . hal02278044

\section{HAL Id: hal-02278044}

\section{https://hal-univ-rennes1.archives-ouvertes.fr/hal-02278044}

Submitted on 18 Nov 2019

HAL is a multi-disciplinary open access archive for the deposit and dissemination of scientific research documents, whether they are published or not. The documents may come from teaching and research institutions in France or abroad, or from public or private research centers.
L'archive ouverte pluridisciplinaire HAL, est destinée au dépôt et à la diffusion de documents scientifiques de niveau recherche, publiés ou non, émanant des établissements d'enseignement et de recherche français ou étrangers, des laboratoires publics ou privés. 


\title{
Bis-thioether containing lipid chains in cationic amphiphiles: physicochemical properties and application for gene delivery
}

\author{
Amal Bouraoui, ${ }^{[a]}$ Rosy Ghanem, ${ }^{[b]}$ Mathieu Berchel, ${ }^{[a]}$ Véronique Vié, ${ }^{[c]}$ Yann Le Guen, ${ }^{[b]}$ Gilles \\ Paboeuf, ${ }^{[c]}$ Laure Deschamps, ${ }^{[a]}$ Tony Le Gall, ${ }^{[b]}$ Tristan Montier, ${ }^{[b]}$ and Paul-Alain Jaffrè s ${ }^{* a]}$
}

\begin{abstract}
Cationic amphiphiles featuring two thioether functions in each lipid chain of bicatenar cationic amphiphiles are herein reported for the first time. The physico-chemical properties and transfection abilities of these new amphiphiles were compared with those of already reported analogues featuring either (i) saturated, (ii) unsaturated or (iii) mono-thioether containing lipid chains. The homogeneity of the series of new compounds allowed to clearly underscore the effect of bis-thioether containing lipid chains. This study shows that besides previous strategies based on unsaturation or ramification, the incorporation of two thioether functions per lipid chain constitutes an original complementary alternative to tune the supramolecular properties of amphiphilic compounds. The potential of this strategy was evaluated in the context of gene delivery and report that two cationic amphiphiles (i.e. $\mathbf{4 a}$ and $\mathbf{4 b}$ ) can be proposed as new efficient transfection reagents.
\end{abstract}

\section{Introduction}

Non-polymeric amphiphilic compounds are molecules constituted by a polar head group covalently attached to one (monocatenar) or several (poly-catenar) hydrophobic chains. There exist many classes of amphiphiles including natural derivatives (e.g. phospholipids, sphingolipids, fatty acids) ${ }^{[1]}$ or synthetic compounds (e.g. bio-inspired phospholipids, ${ }^{[2]}$ Bola lipids, ${ }^{[3]}$ gemini $\left.{ }^{[4]}\right)$. These amphiphiles were used for a multitude of applications including the extraction and stabilization of proteins ${ }^{[5]}$ the stabilization of interfaces (e.g. coaservates ${ }^{[6]}$ ), the design of nano-reactors, ${ }^{[7]}$ the production of vesicles, ${ }^{[8]}$ the production of carriers of nucleic acids delivery ${ }^{[9]}$; others were designed for their own pharmaceutical properties (e.g. bactericidal agents, ${ }^{[10]}$ modulation of ion channels activities, ${ }^{[11]}$ anticancer properties $\left.{ }^{[12]}\right)$. Whatever the application, the physicochemical properties of the amphiphiles must be finely tune to optimize their potential. To this regards, it must be noticing that the structure of the hydrophobic domain has a dramatic effect on the supramolecular properties of the amphiphilic compounds. As an illustration, the number of lipid chains and their length deeply impact the Critical Micellar Concentration (CMC) and the shape

\footnotetext{
[a] A. Bouraoui, Dr. M. Berchel., Dr. L. Deschamps, Prof. Dr. P.A. Jaffrès,

Univ Brest, CNRS, CEMCA, UMR CNRS 6521, 6 Avenue Victor Le Gorgeu, F-29238 Brest, France.

E-mail: pjaffres@univ-brest.fr

[b] R. Ghanem, Y. Le Guen, Dr. T. Le Gall, Prof. Dr. T. Montier INSERM UMR 1078, Université de Brest, IBSAM, UFR Médecine et Sciences de la Santé, CHRU Brest, 22 avenue Camille Desmoulins, F-29238 Brest, France

[c] Dr. V. Vié, G. Paboeuf, Univ Rennes, CNRS, IPR - UMR 6251, ScanMAT - UMS 2001, F35000 Rennes, France
}

of the amphiphiles can impact the structure of the assemblies (e.g. lamellar versus hexagonal). For nucleic acids delivery, cationic amphiphiles ${ }^{[2,13,14]}$ were evaluated for different purposes (lung transfection, ${ }^{[15,16]}$ tendon healing, ${ }^{[17]}$ cancer therapy, ${ }^{[18]}$ anticancer vaccination $^{[19-21]}$ ) and the current developments offer news therapeutic perspectives. It must be emphasized that one of the interest of synthetic vectors, when compared to viral vectors, is that they can be produced on large scale and following simple purification processes. To improve the efficacies of cationic amphiphiles for nucleic acids delivery, both the modification of the structure of the polar head group (e.g. nature of the cationic charge $^{[22]}$ polycationic moieties ${ }^{[23,24]}$ and the structure of the hydrophobic domain were explored. ${ }^{[25]}$ In the last case, it was shown that cationic amphiphiles containing saturated lipid chains produced ineffective pDNA carriers. ${ }^{[26,27]}$ This is likely explained by the fact that the lipoplexes (association of cationic amphiphiles with nucleic acids), generally enter into cells by endocytosis pathway. ${ }^{[28]}$ Subsequently, nucleic acid must escape from endosomes to avoid degradation. This process is likely facilitate by lipid mixing between the cationic amphiphiles and the lipids of the endosomal membrane ${ }^{[29]}$. Therefore, the introduction of some upset within the lipid chains should produce less tight supramolecular packing favoring better lipid mixing. A first strategy to disturb the packing of the lipid chains consists to use unsaturated lipid chains. For that purpose, oleyl chains (C18:1) that possess one unsaturation with a $Z$ configuration are widely employed. ${ }^{[30]}$ As a second strategy, naturally available branched (e.g. phytanyl chains) $)^{[26,31,32]}$ or synthetically prepared ramified (e.g. through thiol-ene click chemistry) lipid chains can be used. ${ }^{[33]}$ The presence of lateral moieties decreases the strength of the packing ${ }^{[34-36]}$ but can also affect the supramolecular organization (e.g. production of inverted hexagonal phase). ${ }^{[33]}$ Beside these two strategies (unsaturation and ramification) the incorporation of poly-unsaturated lipid chains in the structure of cationic amphiphiles was also investigated. These various derivatives were used for $\mathrm{pDNA}^{[16,37,38]}$ or siRNA delivery (the first formulation used for siRNA delivery was recently approved by the FDA for hereditary transthyretin-mediated hATTR amyloidosis). ${ }^{[39,40]}$ It must be however noticed that polyunsaturated lipid chains can be unstable due to their sensitivity to oxidation. Very recently, we investigated an alternative to the use of unsaturation or ramification to modulate the supramolecular packing of cationic amphiphiles. For that purpose, we constructed new lipid chains featuring one thioether function within a linear and saturated hydrophobic chain ${ }^{[41]}$. We demonstrated that the presence of one thioether function did not modify the amphiphilic nature of the molecules but affected their physico-chemical properties (e.g. fluidity and molecular surface area); efficient gene carriers could thus be obtained depending on the position of the thioether function within the lipid chain. These results echo other studies showing that the incorporation of a thioether functional group affected the temperature of fusion of ionic liquids ${ }^{[42]}$ or the 
temperature of transition $\left(\mathrm{T}_{\mathrm{m}}\right)$ of bolaamphiphiles. ${ }^{[43]}$ In the current work, we further investigate the use of thioether function to prepare cationic amphiphiles featuring two such functions in each hydrophobic chain of bicatenar amphiphiles. The first goal of this study was to propose a simple synthesis procedure to prepare lipid chains incorporating two thioether functions and then to incorporate these new lipid chains in the structure of cationic amphiphiles. The second goal consisted to evaluate the different physico-chemical behavior of the new cationic amphiphiles when compared to similar amphiphiles (identical polar head groups) but possessing either saturated, mono-unsaturated lipid chains or lipid chain containing a single thioether function. The third goal consisted to evaluate the transfection efficacies and the cytotoxicity of the new cationic amphiphiles. We also compared their transfection efficacies to the other benchmark (commercial or from our laboratory i.e. "Brest Synthetic Vectors") compounds. To reach these goals, the new cationic amphiphiles (compounds 4a-c; figure 1) were systematically compared to compound BSVS12 (which is an efficient vector for gene delivery and that features one thioether function per lipid chain Erreur ! Signet non défini.[41] and the references compounds BSV36 (incorporating oleyl lipid chains) and BSV101 (featuring stearyl lipid chains). It is worth noticing that all these compounds possess a closely related chemical structures; they all possess the same polar headgroup (trimethylammonium) and spacer (phosphoramidate) varying only according to the number and position of thioether functions within lipid chains of exactly the same length (incorporating 18 atoms in its backbone). These structural similarities are helpful to draw conclusions on the impact of the molecular structural variations (presence of two thioether functions and their location in the hydrophobic chains).

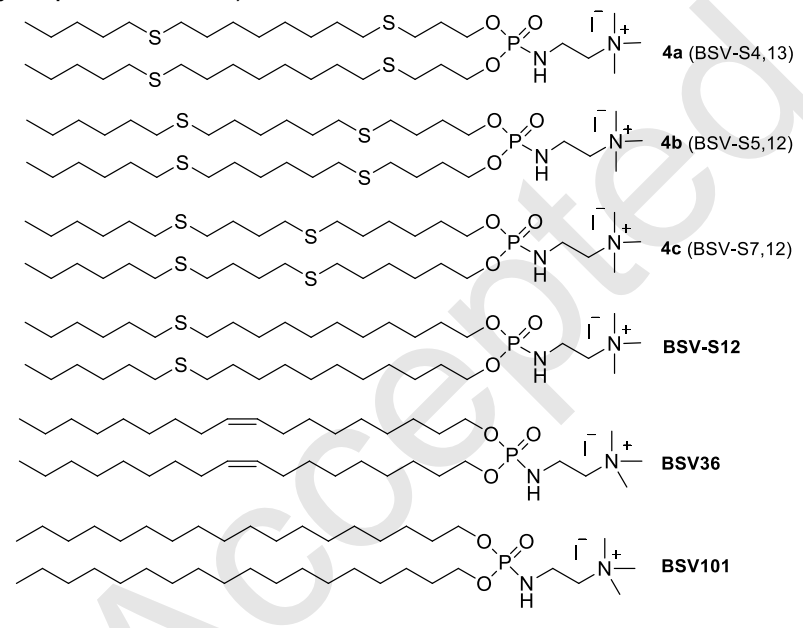

Figure 1. Chemical structure of the new cationic amphiphiles possessing two thioether functions per lipid chain (4a-c) and the reference structure BSV-S12 (one thioether function per lipid chain), BSV36 (oleyl chains) and BSV101 (stearyl chains). ${ }^{2}$

\section{Results and Discussion}

The reaction of alkylthiol with a mono-substituted alkene (terminal alkene) in presence of UV light and with a radical initiator (photo- click reaction) is a regio-selective reaction that produce the linear compound possessing one thioether function. ${ }^{[4,45]}$ This reaction is very efficient and was applied for the synthesis of polymers ${ }^{[46]}$ or dendrimers. ${ }^{[4]}$ With the aim to incorporate two thioether functions within the hydrophobic chains of cationic amphiphiles we investigated their construction by applying a double thiol-ene reaction that involved one $\omega$-alkyl-dithiol and two compounds possessing each a terminal alkene. One of these alkenes possesses one alcohol function in terminal position (Scheme 1) whereas the second alkene is non-functionalized. The thiol-ene reaction was achieved in presence of DMPA (2,2-Dimethoxy-2phenylacetophenone) in presence of UV light $(365 \mathrm{~nm})$ for 18 hours without solvent. We anticipated that this reaction produced three products (statistical reaction): one functionalized with two alcohol functions (side products Aa-c), the desired products (1ac) possessing one alcohol function and the second side product Ba-c that is devoid of any alcohol function. Thanks to their different polarity, these compounds were separated by chromatography to produce compounds 1a-c (Scheme 1) in correct yield ( 45 to $53 \%$ ) and reasonable amount ( 1.2 to $1.5 \mathrm{~g}$ per synthesis). It must be noted that the stoichiometry of the reaction was optimized. We observed that the use 1/1/1 stoichiometry (alkene/dithiol/alkenol) did not produced the best yields (10\%) likely because the alkenes (pentene and hexene) are volatile. In consequence, we increased the quantity of alkene up to 4 equivalents (4/1/2 stoichiometry respectively for alkene/dithiol/alkenol) to obtain better yields (43-53\%). 


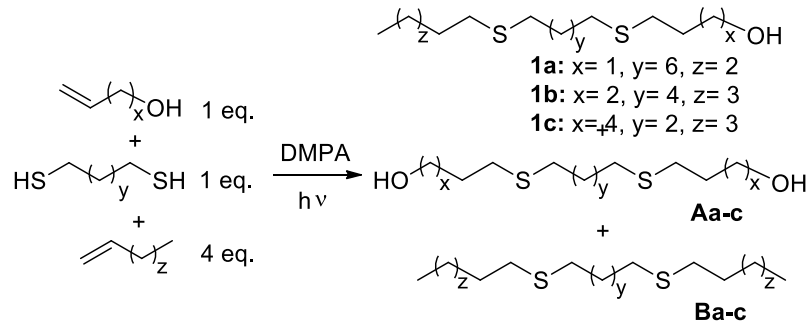$$
\text { 1a-c } \stackrel{(P h O)_{2} P_{-H}^{O}}{O}
$$

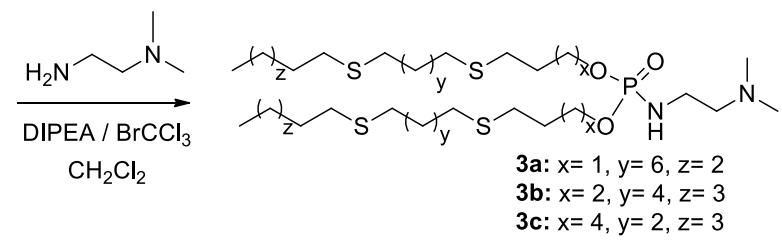

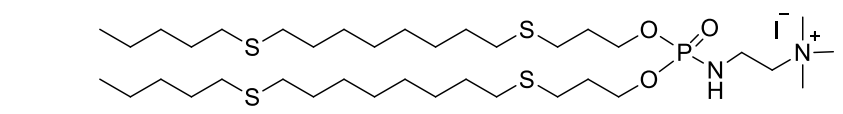

4a (BSV-S4,13)
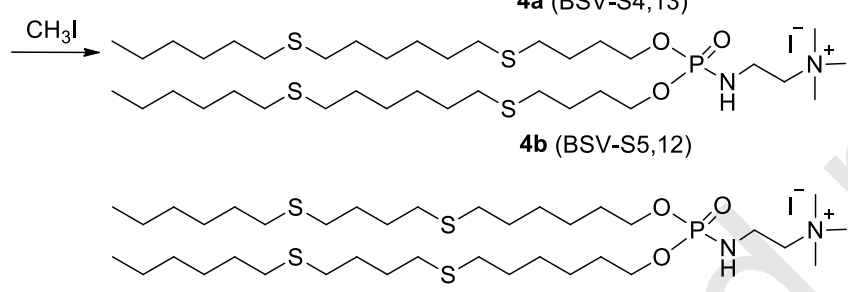

4c (BSV-S7,12)

Scheme 1. Synthesis of the new cationic amphiphiles 4a-c.

Then, we engaged the alcohol 1a-c in a transesterification with diphenylphosphite (reaction without solvent in a kugelroch apparatus following a method previously employed) ${ }^{[48]}$ that produced the phosphite $\mathbf{2 a - c}$ in quantitative yields. The incorporation of the polar head group was then achieved following a two synthesis steps. First, an Atherton-Todd reaction ${ }^{[49]}$ with $\mathrm{N}, \mathrm{N}$-dimethylethylenediamine produced the phosphoramides 3ac in 62 to $72 \%$ yield. In the last step, the more nucleophilic nitrogen atom was alkylated with iodomethane to produce the cationic amphiphiles 4a-c in good yields (95 to $98 \%$ ). Altogether, the new cationic amphiphiles were obtained in four steps with a global yield ranging from 27 to $35 \%$ (synthesis protocols and characterization SI1 and SI2).

The Critical Aggregation Concentration (CAC) of the cationic amphiphiles 4a-c were determined by using Nile red as fluorescent probe that is sensible to the hydrophobic environment. By this method we concluded that all the cationic amphiphilic compounds 4a-c feature a CAC below $2.010^{-5} \mathrm{M}$ (supporting information SI3). The new cationic amphiphiles $\mathbf{4 a - c}$ were formulated as liposomal solutions by hydration of a lipid film. After a hydration period of $18 \mathrm{~h}$ at $4^{\circ} \mathrm{C}$, the solutions were sonicated ( 30 min.) thus producing homogeneous solutions that were characterized by Dynamic Light Scattering (DLS) and zeta potential measurements (Table 1 and SI4). We have previously observed that the cationic lipophosphoramidates possessing one thioether function per hydrophobic lipid chain produced liposomes featuring a sized ranging from 75 to $94 \mathrm{~nm}^{[41]}$ whereas the cationic amphiphiles possessing the same polar head group but oleyl or stearyl lipid chains produced liposomes with size around $200 \mathrm{~nm}$ according to DLS measurements. This trend was confirmed herein, since the cationic amphiphiles $4 a-c$ possess a size ranging from 82 to $89 \mathrm{~nm}$ (Table 1). We can therefore conclude that the phosphoramidate featuring hydrophobic chains functionalized with one or two thioether functions per lipid chain produced, according to our protocol, liposomes featuring a sized below $100 \mathrm{~nm}$. These liposomes, prepared from $\mathbf{4 a - c}$, were kept at $4^{\circ} \mathrm{C}$ for 3 months and only a few differences were observed by DLS and zeta measurements attesting of their stabilities (supporting information SI5). These results suggest that the incorporation of this type of hydrophobic chain could be a strategy to produce liposomes with a small size $(<100 \mathrm{~nm})$. It also suggest that this type of lipid chain accept high curvature when compared to cationic amphiphiles featuring oleyl or stearyl chains. This property can likely be related to the flexibility of the lipid chain. ${ }^{[50]}$ Regarding the zeta potential, all the liposomal solutions prepared have a strong positive zeta potential values as usually observed for cationic liposomes (Table 1).

Then, we recorded the compression isotherms at the air-water interface for the new cationic amphiphiles $\mathbf{4 a - c}$ and the three benchmark compounds (supporting information SI6). The more important data extracted from these isotherms are shown in table 2. First we observed that the minimal surface area at which the surface pressure started to increase $A_{0}$ (lift-off value; Table 2 ) is ranging from 154 to $227 \AA^{2}$ /molecule for the compounds $4 a-c$ (a similar value is observed for BSV S12: $180 \AA^{2} /$ molecule ) whereas this value is $80 \AA^{2} /$ molecule for compound BSV101 (stearyl chains). The presence

Table 1. : Size and zeta potential of the new cationic amphiphiles $4 a-c$ and the benchmark compounds BSV-S12, BSV36 and BSV101.

\begin{tabular}{llll}
\hline & Size $(\mathrm{nm})$ & Pdl & Zeta $(\mathrm{mV})$ \\
\hline 4a (BSV-S4,13) & $89.3 \pm 2.1$ & 0.34 & $+69 \pm 3$ \\
4b (BSV-S5,12) & $83.5 \pm 1.7$ & 0.28 & $+44 \pm 2$ \\
4c (BSV-S7,12) & $82.1 \pm 3.8$ & 0.38 & $+71 \pm 4$ \\
BSV-S12 & $94.0 \pm 1.6$ & 0.34 & $+69 \pm 1$ \\
BSV36 & $200.3 \pm 4.5$ & 0.35 & $+48 \pm 2$ \\
BSV101 & $198.3 \pm 3.3$ & 0.31 & $+59 \pm 1$ \\
\hline
\end{tabular}

of one or two thioether functions per lipid chain (compounds 4a-c and BSV S12) produces amphiphiles that cover a more important surface than BSV101. Weak hydrogen bonds involving the thioether functions and the water surface could explain this behavior. The molecular surface area at the collapse is another 
parameter that indicates how the amphiphiles can reduced their surface area before the monolayer was disrupted. To this respect, the compression isotherms clearly show that the amphiphiles 4ac occupied a lower surface area at the collapse (from 25 to 41 $\AA^{2} /$ molecule) when compared to BSV36 (75 $\AA^{2} /$ molecule) or to a less extent BSV101 (45 $\AA^{2} /$ molecule) or BSV-S12 (45 $\AA^{2} /$ molecule). The differences observed between $\mathbf{4 a - c}$ and BSV$\mathbf{S 1 2}$ indicate that the presence of a second thioether function per lipid chain can provide additional effects. This feature is also consistent with the formation of small liposomes because such supramolecular assemblies require, in the inner leaflet, amphiphilic compounds that occupy a reduced surface area whereas in the outer leaflet the lipid chain have more space due to the curvature. Finally, the surface pressure at the collapse indicates how the supramolecular assembly supports the lateral compression and also indicates on its stability. The more is the pressure at the collapse the more is the film stability. To this respect, the highest surface pressure at the collapse is logically observed for BSV101 that possess C18:0 lipid chains. The cationic amphiphiles $4 a-c$ feature the lowest value (42 to $43 \pm 0.5$ $\mathrm{mN} / \mathrm{m}$ ). These values are even lower than for BSV36 (oleyl chains) and BSV-S12 (one thioether function per hydrophobic chain).

Altogether, the compression isotherms indicate that the hydrophobic chains of compounds $\mathbf{4 a - c}$ are more adaptable to compressive stress than the other lipid chains included in this study (stearyl, oleyl, and mono-thioether lipid chains). The position of the two thioether functions within the hydrophobic chain has in this series of compound a limited impact since compounds 4a-c feature very close behavior at the air-water interface except for the lift-off with values ranging from 154 to 227 $\AA^{2} /$ molecule.
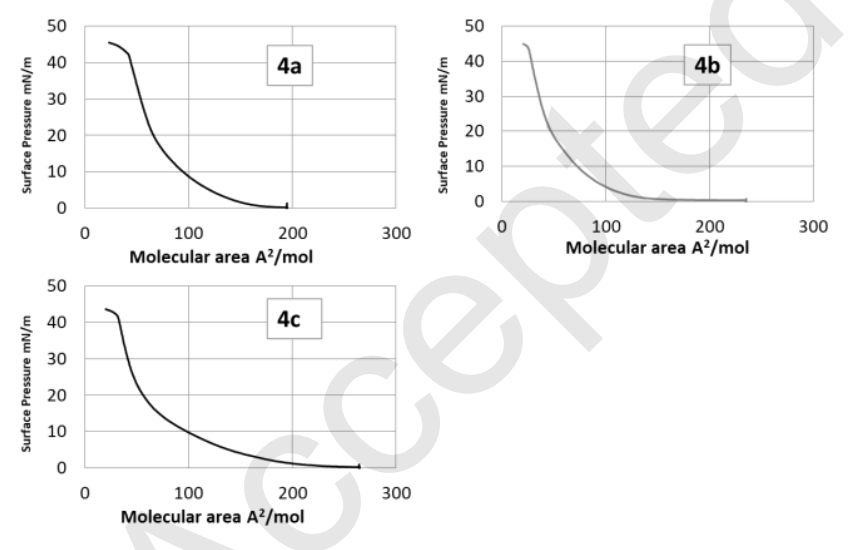

Figure 2. Compression isotherms for the new compounds 4 a-c
Table 2. Principal data extracted from the compression isotherm experiments

Lift off value
$(n=2$ or 3$) A_{0}[a]$
$\AA^{2} /$ molecule
$\pm 2 \AA^{2} /$ molecule

Collapse
molecular area
$(n=2 \quad$ or $\quad 3)$
$\AA^{2} /$ molecule
$\pm 2 \AA^{2} /$ molecule

Collapse

surface

pressure

$(\mathrm{n}=2$ or 3$)$

$\mathrm{mN} / \mathrm{m}$

$\pm 0.25 \mathrm{mN} / \mathrm{m}$

\begin{tabular}{lccc}
\hline 4a (BSV-S4,13) & 165 & 41 & 42 \\
4b (BSV-S5,12) & 154 & 25 & 45 \\
4c (BSV-S7,12) & 227 & 30 & 42 \\
BSV-S12 & 180 & 45 & 47 \\
BSV36 & 160 & 75 & 47 \\
BSV101 & 80 & 45 & 58 \\
\hline
\end{tabular}

[a] Minimal surface area at the surface pressure equal to $0 \mathrm{mN} / \mathrm{m}$.

The reflectivity of the surface (reflective index and thickness) is the property of the film which is detected by measuring the ellipsometric angle (Delta, $\left.{ }^{\circ}\right) .{ }^{[51]}$ These measurements were achieved all along the compression isotherms (simultaneously with the surface pressure) but two important values (at the lowest compression $A_{0}$ (Delta Min), and at the highest compression (Delta max) just before the collapse) are reported in table 3 for each sample (supporting information SI7). The ellipsometric values are correlated to the thickness of the lipid surface at the air-water interface and only the comparison of these values worth to be discussed. It must be emphasis that we hypothesize that all the lipid chains have a comparable reflective index despite the presence of sulfur atom in compound $\mathbf{4 a - c}$ and no sulfur atom in compounds BSV36 and BSV101. First, the delta max values revealed that the presence of one unsaturation (BSV36) deeply limit the thickness of the lipid layer at the highest compression ( $5.8^{\circ}$ for BSV36 when compared to almost $10^{\circ}$ for 4 a-c). The delta max values also indicates that the presence of two thioether functions per lipid chain produced thicker lipid layers. These layers are even thicker than with lipid chain containing only one thioether function (BSV-S12). These results indicate that under lateral pressure the lipid chains possessing two thioether functions can adopt a straight conformation likely orthogonal to the surface thus producing a lipid layer having a comparable thickness than with saturated lipid chain (BSV101). Second, at the lift-off pressure $\left(A_{0}\right)$, as expected all delta values are less than those recorded at higher pressure because the lipid chains have more space and therefore the lipid monolayer is less thick. However, we can emphasis some marked differences depending on the structure of the lipid chain. With the saturated lipid chains (BSV101), the ellipsometric angle is up to 3 times higher than for the compounds $\mathbf{4 a - c}$. This suggests that compounds $4 \mathbf{a}-\mathbf{c}$ at low compression pressure can cover more surface than with the saturated lipid chains (BSV101). This could be explained by the presence of weak hydrogen bonds between the thioether function and the water surface. The presence of one unsaturation (BSV36) produces reflexivity comparable to those recorded for compounds 
4a-c meaning that at low pressure the thickness of the layer should be comparable. The last column of Table 3 reports the difference between maximal and minimal ellipsometric angle $\left(\delta \Delta,{ }^{\circ}\right)$. More this difference is high more the lipid can adapt its conformation to respond to the lateral pressure. To this respect, compounds $4 \mathrm{a}-\mathrm{c}$ features the highest difference. Considering that the polar head groups are identical in all this series of cationic amphiphiles whereas the volume occupied by the lipid chains varies depending on the lateral pressure we can conclude that these amphiphiles $\mathbf{4 a - c}$ could have a positive curvature or a negative curvature depending on the constrain. ${ }^{52]}$ This adaptability could favor the stabilization of nanoparticles with higher curvatures and could explain the formation of smaller supramolecular assemblies with the compounds 4a-c (Table 1).

2

Table 3. Ellipsometry results extracted from compression isotherms.

\begin{tabular}{lrrl}
\hline & $\begin{array}{l}\text { Delta min } \\
(\mathrm{n}=2 \text { or } 3) \\
\Delta,^{\circ}\end{array}$ & $\begin{array}{l}\text { Delta max } \\
(\mathrm{n}=2 \text { or } 3) \\
\Delta^{\circ}{ }^{\circ}\end{array}$ & $\begin{array}{l}\text { Delta max } \\
\text { Delta min } \\
\delta \Delta,{ }^{\circ}\end{array}$ \\
\hline 4a (BSV-S4,13) & $3.6 \pm 0.1$ & $10.1 \pm 0.2$ & $6.5 \pm 0.2$ \\
4b (BSV-S5,12) & $2.0 \pm 0.1$ & $9.8 \pm 0.1$ & $7.8 \pm 0.1$ \\
4c (BSV-S7,12) & $3.3 \pm 0.1$ & $10.6 \pm 0.1$ & $7.3 \pm 0.1$ \\
BSV-S12 & $1.5 \pm 0.1$ & $7.7 \pm 0.1$ & $6.2 \pm 0.1$ \\
BSV36 & $3.5 \pm 0.1$ & $5.8 \pm 0.1$ & $2.3 \pm 0.1$ \\
BSV101 & $6.1 \pm 0.1$ & $9.3 \pm 0.1$ & $3.2 \pm 0.1$ \\
\hline
\end{tabular}

[a] Delta at the Minimal surface area at the surface pressure equal to 0 $\mathrm{mN} / \mathrm{m}$. [b] Delta at high pressure (just before the collapse).

Fluorescence anisotropy of a hydrophobic probe is another technic that can be used to assess the rigidity/fluidity of the nonpolar domains of supramolecular assembly of amphipiles. For that purpose the compounds $4 \mathrm{a}-\mathrm{c}$ were formulated as liposomal solutions and the fluorescent probe diphenylhexatriene (DPH) was added. ${ }^{[53]}$ We recorded the anisotropy of fluorescence of liposomes $4 \mathrm{a}-\mathrm{c}$ in water from 5 to $65^{\circ} \mathrm{C}$ (Figure 3 and supporting information S18). We observed that the compounds $4 a-c$ exhibited a low anisotropy but no transition between a gel to a liquid phase was detected in the range of temperature considered suggesting that the main transition $(\mathrm{Tm})$ was below $5^{\circ} \mathrm{C}$. This result contrast with our previous study reporting a transition at $16^{\circ} \mathrm{C}$ for BSV-S12 We can conclude that the compound $\mathbf{4 a - c}$ exist in a fluid phase at temperature upper than $5^{\circ} \mathrm{C}$. This result is fully consistent with the compression isotherms that concluded that the amphiphiles $4 a-c$ were very flexible and more fluid than the compounds featuring only one thioether function per lipid chain (BSV-S12) as shown by the pressure at the collapse, which is lower for the compounds 4a-c. We can therefore conclude on a cumulative effect induced by increasing the number of thioether function per lipid chain on the fluidity of the hydrophobic domains.

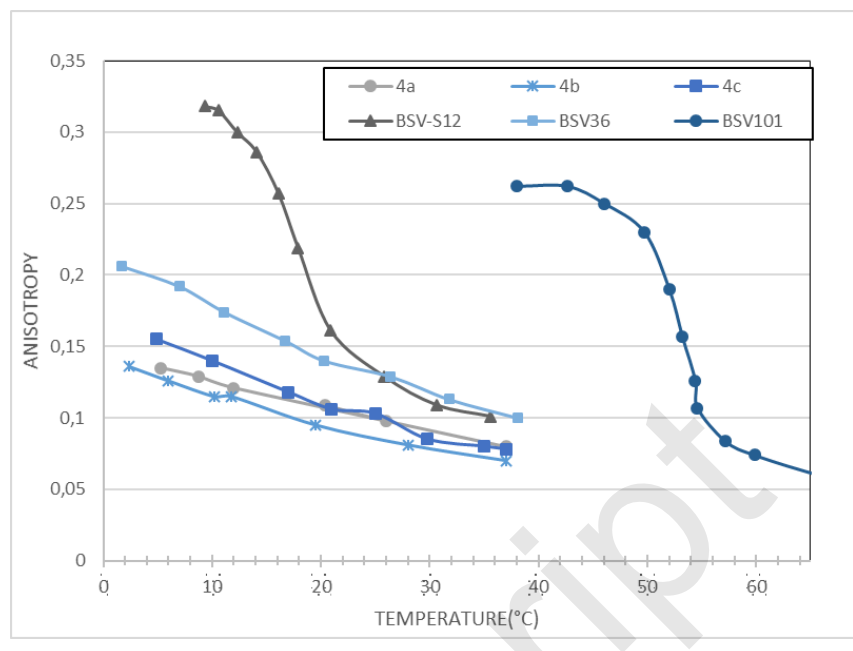

Figure 3. Fluorescence anisotropy from 2 to $65^{\circ} \mathrm{C}$ for liposomal solution (20 $\mathrm{mM}$ ) with $0.5 \%$ of $\mathrm{DPH}$ as fluorescent probe.

The physicochemical characterizations of the cationic amphiphiles 4a-c emphasize the specificities induced by the presence of two thioether functions within the lipid chains. We have shown an increase of the fluidity and a capacity to adapt the conformation of the lipid chains when a lateral pressure is applied. All these features prompt us to explore the use of these cationic amphiphiles as nucleic acids' carriers. Indeed, the adaptability of the conformation of the lipid chains should stabilize the nanoparticles formed by the auto-assembly of a plasmid DNA (pDNA) with cationic amphiphiles (lipoplexes). On the other hand, the fluidity should favor the escape of the lipoplexes from the endosomes after cell internalization. First, we assessed the capacity of the cationic amphiphiles $4 a-c$ to compact pDNA by mixing these amphiphiles at different charge ratio (CR) with a pDNA (pGM144 ${ }^{[54]}$ ). DLS measurments of the lipoplexes prepared at different $\mathrm{CR}(\mathrm{CR}=2,4,6)$ (supporting materials SI9) indicated an increase of the size whereas the zeta potential consistently increased from $C R=2$ to $C R=6$. As shown with the electrophoresis gel retardation assays (Figure 4A), all three compounds 4a-c were able to compact pDNA. A full compaction was observed at $\mathrm{CR}=2$ for $\mathbf{4 b}$ and $\mathbf{4 c}$ whereas it was observed at $C R=4$ for $\mathbf{4 a}$. The addition of the polyanionic polymer dextran sulfate (ds) on preformed lipoplexes $(C R=4)$ allowed to restore the migration of free pDNA as shown in figure 4B. By contrast, only very partial pDNA release was observed after addition of dextran sulfate on BSV101 lipoplexes, suggesting a stronger compaction within such complexes (Supporting Information SI10). 
A)

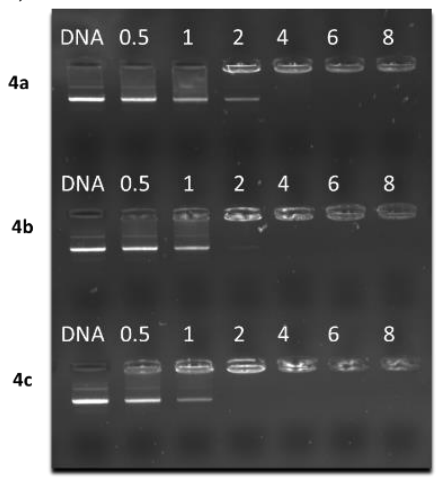

B)

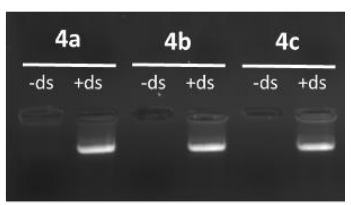

expressed as the Relative Light Units/mg of total proteins, as the mean \pm SD of 3 wells.

In parallel, cells viability was measured under identical experimental conditions, i.e. $24 \mathrm{~h}$ after transfection with lipoplexes formed at the same CR as before (CR 2, 4 and 6). As for 16HBE and $\mathrm{A} 549$ cell lines, the results showed that $\mathbf{4 a}$ and $\mathbf{4 c}$ were almost safe (with cell viabilities remaining between 80 to $100 \%$ ). However, 4b used at CR 4 exhibited some toxicity towards A549 (with about $60 \%$ of viability). Unexpectedly, for a higher CR, $\mathbf{4 b}$ and BSV-S12 were found less toxic towards A549. It is noteworthy that the best transfection efficiencies were measured at $\mathrm{CR}=4$, for which cell viability was in most of the cases the lowest. For instance, compound $\mathbf{4 b}$ was both less efficient and less cytotoxic when increasing the CR above 4 (i.e. at CR 6). As

Figure 4. A) DNA binding ability of compounds $4 a-c$ at charge ratio $(C R)=0.5$ $1,2,4,6$ and 8 . B) Gel electrophoresis of lipoplexes prepared at $C R=4$ in the absence (-ds) and in presence (+ds) of dextran sulfate. The pGM144 pDNA was used in all these experiments.

The newly reported cationic amphiphiles 4a-c were evaluated as regards their ability to deliver the luciferase-encoding pDNA pGM144 in three different cell lines (A549, C2C12 and 16HBE). These transfections were achieved at different charge ratio (from 0.5 to 8). It was observed that the best CR was 4 in term of transfection efficacies. Accordingly, we present in figure 5 , the transfection results at CR 4 for $\mathbf{4 a - c}$ and three reference compounds. All the transfection assays were achieved the same day under identical experimental conditions thus allowing to make a straight comparison of the transfection efficacies. It must be emphasized that BSV36 was previously compared to Lipofectamine ${ }^{[26]}$ and also to the benchmark compound from our laboratory (KLN47) and demonstrated its efficacy. ${ }^{[55]}$ The results obtained indicate that the transfection efficacy was dependent of the cell line (A549 and 16HBE were more easily transfected than $\mathrm{C} 2 \mathrm{C} 12)$. The most efficient carriers were $\mathbf{4 a}$ and $\mathbf{4 b}$, irrespective of the cell line considered.

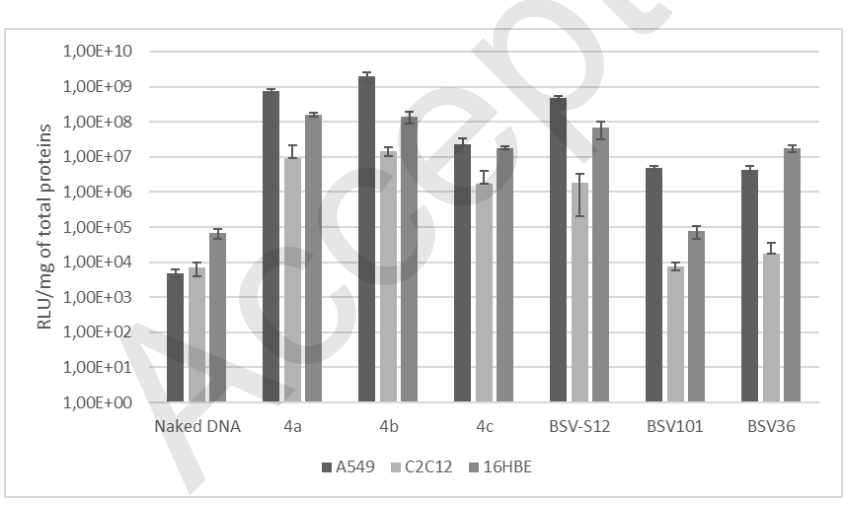

Figure 5. Transfection efficiency of compounds $\mathbf{4 a}, \mathbf{4 b}$ and $\mathbf{4 c}$ in comparison to BSV-S12 and two references BSV101 and BSV36 at CR=4 on three different cell lines (A549, C2C12 and 16HBE). As negative control, free pDNA (pGM144, luciferase-encoding plasmid, $0.25 \mu \mathrm{g} /$ well) was used. $24 \mathrm{~h}$ after deposition, transfection efficiency was determined by luciferase assay. Results are

for $\mathrm{C} 2 \mathrm{C} 12$, it appeared to be more sensitive to all lipoplexes, especially $\mathbf{4 b}$, independently of the CR used.

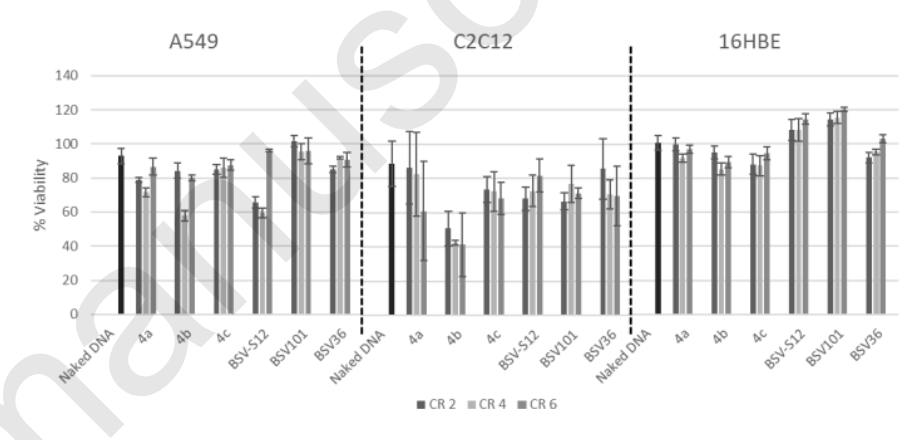

Figure 6. Cell viability of $\mathrm{A} 549, \mathrm{C} 2 \mathrm{C} 12$ and $16 \mathrm{HBE} 24 \mathrm{~h}$ after treatment with lipoplexes formed at different CR (2, 4 and 6). Naked pDNA was used as negative control. Results are expressed as a percentage of the viability determined with un-transfected cells, as the mean \pm SD of 3 wells.

\section{Conclusions}

The synthesis of hydrophobic chains that incorporate two thioether functions can be readily achieved by using a statistical double thiol-ene photo-click reaction. Accordingly, the structure of the dithiol used as substrate defines the number of methylene units that separate the two thioerther functions in the final hydrophobic chain. Bicatenar cationic amphiphiles possessing these thioether-functionalized hydrophobic chains were synthesized. These cationic amphiphiles can more easily adapt the conformation of their lipid chain to support lateral pressure as illustrated by the lower value of the molecular surface area at the collapse for 4a-c when compared to BSV101, BSV36 and BSVS12. This adaptability to the lateral pressure is also evidenced by the thickness of the supramolecular assemblies (determined by ellipsometric measurements) at the air-water interface. To this respect, the cationic amphiphiles possessing the new lipid chains (4a-c) feature the highest adaptability when compared to cationic amphiphiles possessing oleyl chains (BSV36) or stearyl chains 
(BSV101). The fluorescence anisotropy also emphasizes the additional effect induced by the presence of two thioether functions per lipid chain as shown by the lower values of the transition between rigid to fluid phase. All these physico-chemical properties suggest that the incorporation of two thioether functions per hydrophobic chain (4a-c), in place of one (BSV-S12), renders the supramolecular assembly more fluid, with a greater adaptability to lateral pressure (lower molecular surface at the collapse, lower value of the pressure at the collapse, higher variation of the ellipsometry angles). The incorporation of two thioether functions in the hydrophobic domain thus represents another alternative for modulating the strength of the resulting supramolecular assemblies. The effect of subsequent properties towards gene transfection activity was evaluated. We report that two of the new compounds described herein (i.e. $\mathbf{4 a}$ and $\mathbf{4 b}$ ) are among the most efficient to transfect three animal or humanderived cell lines.

\section{Experimental Section}

\section{Synthesis - General protocols}

Synthesis of compounds 1a-c: Alkenol (1 equivalent), alkene (4 equivalents) and alkanedithiol (1 equivalent) were placed in a Schlenk tube (pyrex) with 2,2-dimethoxy-2-phenylacetophenone DMPA (0.4 equivalent) and degassed under argon for $10 \mathrm{~min}$. The UV Lamp was a Phillips TL-D $18 \mathrm{~W} / 08 \mathrm{BLB}(\lambda=365 \mathrm{~nm})$ that was placed close to the Schlenk tube $(\approx 1$ $\mathrm{cm})$. The mixture was then placed under UV light at $18-20^{\circ} \mathrm{C}$ for $18 \mathrm{~h}$. The crude product was purified using flash chromatography Hexane/AcOEt to give the desired product.

Synthesis of compounds 2a-c: Compound $\mathbf{1}$ (2.2 equivalent) and diphenyl phosphite (1 equivalent) were mixed and heated at $130^{\circ} \mathrm{C}$ in a Kugelroch distillation apparatus under reduced pressure $\left(4.210^{-2} \mathrm{mbar}\right)$ for $3 \mathrm{~h}$. Phenol is removed by distillation. The undistilled compound correspond to the desired products $2 \mathbf{a}-\mathbf{c}$. They were used without further purification.

Synthesis of compounds 3a-c: To a solution of compound 2 (1 equivalent) in $\mathrm{CH}_{2} \mathrm{Cl}_{2}$ was added $\mathrm{N}, \mathrm{N}$-dimethylethylenediamine (1.1 equivalent), DIPEA (1.1 equivalent) and $\mathrm{BrCCl}_{3}$ (1.1 equivalent) at $0^{\circ} \mathrm{C}$. The reaction was stirred for $15 \mathrm{~min}$. at $0^{\circ} \mathrm{C}$ then for $4 \mathrm{~h}$ at $20^{\circ} \mathrm{C}$. The solvent was evaporated and replaced by diethylether. After agitation for $10 \mathrm{~min}$. the solution was filtrated and the filtrated was concentrated. The residue was then redissolved in $\mathrm{CH}_{2} \mathrm{Cl}_{2}$, washed with water, dried over $\mathrm{MgSO}_{4}$ filtered and concentrated. The compounds were purified by silica gel chromatography using $\mathrm{CH}_{2} \mathrm{Cl}_{2} / \mathrm{MeOH}: 90 / 10(\mathrm{v} / \mathrm{v})$ as eluent to produce 3ac as a colourless viscous oil. The purification by chromatography at this step is important because in the next step (see below), the purification consisted to remove all the volatile compounds.

Synthesis of compounds $\mathbf{4 a - c :}$ : To a solution of compound $\mathbf{3}$ ( 1 equivalent) in $\mathrm{CH}_{2} \mathrm{Cl}_{2}$ was added methyl iodide (4 equivalents). The reaction was stirred overnight at $20^{\circ} \mathrm{C}$. The solvent and the excess of methyl iodide were evaporated by leaving under vacuum for 2 to $5 \mathrm{~h}$ in order to remove all the volatiles (solvent and excess of methyl iodide) that are the only chemicals present in the crude product. No additional purification was needed. The compound $4 \mathrm{a}-\mathrm{c}$ were isolated as pale yellow waxes.

\section{Compression isotherms}

The Langmuir trough was cleaned with ethanol and water then it was filled with the sub-phase (ultrapure water). A good base line in the ( $\pi-A)$ and $(\Delta-A)$ isotherms indicated the cleanliness of the interface. The cationic lipid in $\mathrm{CHCl}_{3} / \mathrm{MeOH}(2 / 1)$ mixture $(25 \mu \mathrm{L})$ was slowly spread at the air-water interface using a Hamilton micro syringe. After waiting 10 minutes till the solvents evaporate, the isotherm of the lipid monolayer was recorded by compressing the barriers at the rate of $5 \mathrm{~cm}^{2} / \mathrm{min}$. The surface pressure was measured using a filter paper held by a Wilhelmy balance connected to a microelectronic feedback system (Nima technology). The experiment is stopped once the collapse is reached.

\section{Ellipsometry}

The ellipsometric measurements were carried out with a home-made ellipsometer associated to the Langmuir trough and the tensiometer. The software developed recorded simultaneously the value of the surface pressure and the value of the ellipsometric angle during the isotherm compression. The principal of the ellipsometric angle measurement is the following: a polarized He-Ne laser beam $(\lambda=632.8 \mathrm{~nm}$, Melles Griot, Carlsbad, CA) is reflected by the air/water interface. The incidence angle of the light was $1^{\circ}$ away from the Brewster angle $\left(53.12^{\circ}\right.$ value obtained for an air/water interface). After reflection, the laser light passed through a N/4 retardation plate, a Glan-Thompson analyzer, and a photomultiplier. Through a computer-controlled feedback loop, the analyzer automatically rotated toward the extinction light position. In this "null ellipsometer" configuration, the analyzer angle, multiplied by 2 , yielded the value of the ellipsometric angle $(\Delta)$, i.e., the phase difference between parallel and perpendicular polarization of the reflected light, which reflects the thickness of the molecular film adsorbed at the interface. The laser beam probed a surface of $1 \mathrm{~mm}^{2}$ and a depth of the order of $1 \mu \mathrm{m}$. Values of $\Delta$ were recorded every $4 \mathrm{~s}$ with a precision of $\pm 0.5^{\circ}$.

\section{Determination of CAC and Fluorescence anisotropy}

Fluorescence was recorded on Agilent Cary Eclipse Fluorescence Spectrophotometer, using automatic polarizers for anisotropy measurements. The fluorescent probe 1,6-diphenylhaxatriene (DPH) was used for anisotropy measurements whereas the solvatochromic fluorescent probe Nile red was used for Critical Aggregation Concentration (CAC) determination. Both were purchased from Sigma-Aldrich.

\section{Size and zeta measurements}

Size and zeta measurements were achieved with a MALVERN Nano ZS.

\section{Compaction of pDNA}

Lipoplexes were prepared by mixing pDNA (pGM144 $-3.7 \mathrm{~kb}$ ) ${ }^{[54]}$ with each liposomal solution in water, for concentrations corresponding to $\mathrm{CR}$ ranging from 0.5 to 8 . The resulting mixtures were incubated at room temperature for 30 minutes before being subjected to electrophoresis in a $0.8 \%$ agarose gel at $100 \mathrm{~V}, 90 \mathrm{~mA}$. The gel previously stained with ethidium bromide nuclei acids gel staining (Dominique Deutsher) was visualized using a UV transilluminator (Fisher Bioblock). In order to determine the recover free pDNA from preformed lipoplexes, dextran sulfate was mixed with the latter and incubated for $30 \mathrm{~min}$ at room temperature. Electrophoresis was then performed as detailed before.

\section{Transfection}

The in vitro reporter gene assay via luciferase measurement was carried out as previously reported. ${ }^{[16]}$ In short, the three cell lines were grown in either EMEM (16HBE) or DMEM (A549 and C2C12) both supplemented 
with $10 \%$ bovine fetal serum, $1 \%$ antibiotic and $1 \%$ L-glutamine. All incubations were performed at $37^{\circ} \mathrm{C}$ in a humidified atmosphere containing $5 \% \mathrm{CO}_{2}$. The day before transfection, the cells were seeded into a 96-well plate at a density of 20000 cells per well for A549 and C2C12 and 40000 cells per well for $16 \mathrm{HBE}$. Lipoplexes were prepared as detailed above and then added dropwise into each well; the reference compound BSV36 was used as a positive transfection control whereas naked DNA was used as a negative control. After $24 \mathrm{~h}$ at $37^{\circ} \mathrm{C}$, the culture medium was removed and the cells were lysed with Passive Lysis Buffer (Promega) prior to running a chemiluminescence assay (Luciferase Assay System, Promega) to determine luciferase expression. The total protein content of each cell lysate was determined using the BC assay kit (Uptima). Finally, data were expressed as relative light units (RLU) per milligram of total proteins (mean $\pm \mathrm{SD}$ with $\mathrm{n}=3$ ).

\section{Cell viability}

The ViaLight kit (Lonza) was used to determine the ATP content which reflects the number of living cells (transfected or not) in culture. The latter is the result of both cell proliferation and cell mortality that occurred during the experiment. This assay was used as recommended by the manufacturer. The results were expressed as percentages relative to the viability of non-transfected cells used as reference ( $100 \%$ cell viability).

\section{Acknowledgements}

We thank Association Française contre les Myopathies (AFMFrance), Association Gaétan Saleün (Brest-France), Vaincre La Mucoviscidose (Paris, France), CNRS and INSERM for funding. $R G$ is grateful for a $\mathrm{PhD}$ fellowship from Brest Métropole and Association Gaétan Saleün. We thank the platforms (RMN-RPE and spectrométrie de masse) from the University of Brest.

Keywords: cationic amphiphiles • lipid • thioether • supramolecular chemistry $\bullet$ transfection

[1] R. Pichot, R.L. Watson, I.T. Norton, Int. J. Mol. Sci., 2013, 14, $11767-$ 11794.

[2] M. Berchel, T. Le Gall, H. Couthon-Gourvès, J.P. Haelters, T. Montier, P. Midoux, P. Lehn, P.A. Jaffrès, Biochimie, 2012, 94, 33-41.

[3] S. Drescher, C. Otto, S. Müller, V.M. Garamus, C.J. Garvey, S. Grünert, A. Lischka, A. Meister, A. Blume, B. Dobner, Langmuir, 2018, 34, 43604373.

[4] M. Damen, A. J. J. Groenen, S. F. M. van Dongen, R. J. M. Nolte, B. J. Scholte, M. C. Feiters, MedChemComm, 2018, 9, 1404-1425.

[5] G.G. Privé, Methods, 2007, 41, 388-397.

[6] J.P. Douliez,N. Martin, C. Gaillard, T. Beneyton, J.C. Baret, S. Mann,L. Beven, Angew. Chem. Inter. Ed., 2017, 56, 13689-13693.

[7] L. Schoonen, J.C.M. van Hest, Adv. Mater., 2016, 28, 1109-1128.

[8] D. Lombardo, M. A. Kiselev, S. Magazù, P. Calandra, Adv. Cond. Matter Phys., 2015, 151683.

[9] a) X. Guo, L. Huang Acc. Chem. Res., 2012, 45, 971-979 b) C. Liu, L. Zhang, H. Liu, K. Cheng, J. Controlled Rel., 2017, 266, 17-26 c) Y. Rui, D.R. Wilson, J.J. Green, Trends Biotechnol., 2019, 37, 281-293.

[10] T. Le Gall, M. Berchel, S. Le Hir, A. Fraix, J.Y. Salaün, C. Férec, P. Lehn, P.A. Jaffrès, T. Montier, Adv. Healthcare Mater, 2013, 2, 1513-1524

[11] a) A. Girault, J.P. Haelters, M. Potier, A. Chantôme, M. Pineau, S. Marionneau-Lambot, T. Oullier, G. Simon, H. Couthon-Gourvès, P.A. Jaffrès, V. Joulin, B. Corbel, P. Bougnoux, C. Vandier, Current Cancer Drug Target, 2011, 11, 1111-1125 ; b) A. Chantôme, M. Potier-Cartereau, L. Clarysse, G. Fromont, S. Marionneau-Lambot, M. Guéguinou, J.C.
Pagès, C. Collin, T. Oullier, A. Girault, F. Arbion, J.P. Haelters, P.A Jaffrès, M. Pinault, P. Besson, V. Joulin, P. Bougnoux, C. Vandier Cancer Research, 2013, 73, 4852-61.

[12] a) P. Ríos-Marco, C. Marco, X. Gálvez, J. M. Jiménez-López, M. P. Carrasco, Biochim. Biophys. Acta, 2017, 1859, 1657-1667; b) P.A Jaffrès, C. Gajate, A.M. Bouchet, H. Couthon-Gourvès, A. Chantôme, M Potier-Cartereau, P. Besson, P. Bougnoux, F. Mollinedo, C. Vandier, Pharm. Ther., 2016, 165, 114-131.

[13] B. Draghici, M.A. llies, J. Med. Chem., 2015, 58, 4091-4130.

[14] M. Damen, A.J.J. Groenen, S.F.M. van Dongen, R.J.M. Nolte, B.J. Scholte, M.C. Feiters, Med. Chem. Commun., 2018, 9, 1404-1425.

[15] N. Belmani, P. Midoux, C. Pichon, P. Loyer, C. Passirani, T. Le Gall, P.A Jaffrès, P. Lehn, T. Montier, Biotechnol. J., 2015, 10, 1370-1389.

[16] T. Le Gall, D. Loizeau, E. Picquet, N. Carmoy, J.J. Yaouanc, L. Deschamps, P. Delépine, P. Giamarchi, P.A. Jaffrès, P. Lehn, T. Montier, J. Med. Chem. 2010, 53, 1496-1508.

[17] A. Delalande, M.P. Gosselin, A. Suwalski, W. Guilmain, C. Leduc, M. Berchel, P.A. Jaffrès, P. Baril, P. Midoux, C. Pichon, Nanomedicine: NBM, 2015, 11, 1735-1744.

[18] Y. Xiao, K. Shi, Y. Qu, B. Chu, Z. Qian, Mol. Ther. Methods Clin. Dev., 2018, 12, 1-18.

[19] K. Van der Jeught, S. De Koker, L. Bialkowski, C. Heirman, P. Tjok Joe, F. Perche, S. Maenhout, S. Bevers, K. Broos, K. Deswarte, V. Malard, H. Hammad, P. Baril, T. Benvegnu, P.A. Jaffrès, S.A.A. Kooijmans, R Schiffelers, S. Lienenklaus, P. Midoux, C. Pichon, K. Breckpot, K. Thielemans, ACS Nano, 2018, 12, 9815-9829.

[20] A. Le Moignic, V. Malard, T. Benvegnu, L. Lemiègre, M. Berchel, P.A Jaffrès, C. Baillou, M. Delost, R. Macedo, J. Rochefort, G. Lescaille, C Pichon, F.M. Lemoine, P. Midoux, V. Mateo, J. Control Release, 2018 278, 110-121.

[21] P. Midoux, C. Pichon, Expert Rev. Vaccines., 2015, 14, 221-34.

[22] V.D. Sharma, J. Lees, N. E. Hoffman, E. Brailoiu, M. Madesh, S. L. Wunder, M. A. Ilies, Mol. Pharm., 2014, 11, 545-559.

[23] M. Mével, T. Montier, F. Lamarche, P. Delépine, T. Le Gall, J.J. Yaouanc P.A. Jaffrès, D. Cartier, P. Lehn, J.C. Clément, Bioconjugate Chem. 2007, 18, 1604-1611.

[24] S. S. Le Corre, N. Belmadi, M. Berchel, T. Le Gall, J.P. Haelters, P. Lehn, T. Montier, P.A. Jaffrès, Org. Biomol. Chem., 2015, 13, 1122-1132.

[25] S. Fujii, S. Yamada, M. Araki, J.H. Lee, R. Takahashi, S. Sakurai, Langmuir, 2019, 35, 3156-3161.

[26] S.S. Le Corre, M. Berchel, N. Belmadi, C. Denis, J.P. Haelters, T. Le Gall, P. Lehn, T. Montier, P.A. Jaffrès, Org. Biomol. Chem., 2014, 12, 14631474.

[27] B. Moghaddam, S. E. McNeil, Q. Zheng, A. R. Mohammed, Y. Perrie, Pharmaceutics, 2011, 3, 848-864.

[28] L. Billiet, C. Gonçalves, J.P. Gomez, J. Lodewick, M. Berchel, P.A Jaffrès, T. Montier, P. Lehn, E. Bertrand, Y. El-Ghoul, H. Cheradame, P. Guégan, M. Mével, B. Pitard, T. Benvegnu, C. Pichon, P. Midoux Biomaterials, 2012, 33, 2980-2990.

[29] Y.H. Xu, F.C. Szoka, Biochemistry, 1996, 35, 5616.

[30] D.F. Zhi, S.B. Zhang, B. Wang, Y.N. Zhao, B.L. Yang, S.J. Yu, Bioconjugate Chem., 2010, 21, 563-577.

[31] S. S. Le Corre, M. Berchel, T. Le Gall, J.P. Haelters, P. Lehn, T. Montier, P.A. Jaffrès, Eur. J. Org. Chem., 2014, 8041-8048.

[32] L. Wang, R. Koynova, H. Parikh, R.C. MacDonald, Biophys. J., 2006, 91 3692-3706

[33] D. Afonso, T. Le Gall, H. Couthon-Gourvès, A. Grélard, S. Prakash, M. Berchel, N. Kervarec, E.J. Dufourc, T. Montier, P.A. Jaffrès, Soft Matter, 2016, 12, 4516-4520.

[34] D. Poger, B. Caron, A.E. Mark, J. Phys. Chem. B, 2014, 118 13838-13848.

[35] M. Lindberg, N. Carmoy, T. Le Gall, A. Fraix, M. Berchel, C. Lorilleux, H. Couthon-Gourvès, P. Bellaud, A. Fautrel, P.A. Jaffrès, P. Lehn, T Montier, Biomaterials, 2012, 33, 6240-6253. 
[36] M. J. Moghaddam, L. de Campo, L.J. Waddingtonc, C.J. Drummond, Soft Matter, 2010, 6, 5915-5929.

[37] A. Tschiche, S. Malhotra, R. Haag, Future Medicine, 2014, 9, 667-693.

[38] N.L. Benner, K.E. Near, M.H. Bachmann, C.H. Contag, R.M. Waymouth, P.A. Wender, Biomacromolecules, 2018, 19, 2812-2824.

[39] S.C. Semple, A. Akinc, J. Chen, A.P. Sandhu, B.L. Mui, C.K. Cho, D.W Sah, D. Stebbing, E.J. Crosley, E. Yaworski, I.M. Hafez, J.R. Dorkin, J. Qin, K. Lam, K.G. Rajeev, K.F. Wong, L.B. Jeffs, L. Nechev, M.L. Eisenhardt, M. Jayaraman, M. Kazem, M.A. Maier, M. Srinivasulu, M.J. Weinstein, Q. Chen, R. Alvarez, S.A. Barros, S. De, S.K. Klimuk, T. Borland, V. Kosovrasti, W.L. Cantley, Y.K. Tam, M. Manoharan, M.A Ciufolini, M.A. Tracy, A. de Fougerolles, I. MacLachlan, P.R. Cullis, T.D. Madden, M.J. Hope, Nat. Biotechnol., 2010, 28, 172-6.

[40] D. Adams, A. Gonzalez-Duarte, W.D. O'Riordan, C.C. Yang, M. Ueda, A.V. Kristen, I. Tournev, H.H. Schmidt, T. Coelho, J.L. Berk, K.P. Lin, G. Vita, S. Attarian, V. Planté-Bordeneuve, M.M. Mezei, J.M. Campistol, J. Buades, T.H. Brannagan, B.J. Kim, J. Oh, Y. Parman, Y. Sekijima, P.N. Hawkins, S.D. Solomon, M. Polydefkis, P.J. Dyck, P.J. Gandhi, S. Goyal, J. Chen, A.L. Strahs, S.V. Nochur, M.T. Sweetser, P.P. Garg, A.K. Vaishnaw, J.A. Gollob, O.B. Suhr., N. Engl. J. Med., 2018, 379, 11-21.

[41] A. Bouraoui, M. Berchel, R. Ghanem, V. Vié, G. Paboeuf, L. Deschamps, O. Lozach, T. Le Gall, T. Montier, P.A. Jaffrès, Org. Biomol. Chem., 2019 17, 3609-3616.

[42] R. A. O’Brien, A. Mirjafari, K.M. Mattson, S.M. Murray, N. Mobarrez, E.A. Salter, A. Wierzbicki, J.H. Davis, K.N. West, J. Phys. Chem. B, 2014, 118, 10232-10239.

[43] S. Drescher, A. Meister, G. Graf, G. Hause, A. Blume, B. Dobner, B., Chem. Eur. J., 2008, 14, 6796-6804.

[44] C.E. Hoyle, C.N. Bowman, Angew. Chem. Int. Ed. Engl., 2010, 49, 1540 73.
[45] M. Berchel, T. Le Gall, O. Lozach, J.P. Haelters, T. Montier, P.A. Jaffrès, Org. Biomol. Chem., 2016, 14, 2846-53.

[46] T.O. Machado, C. Sayer, P.H.H. Araujo, Eur. Polymer J., 2017, 86, 200 215.

[47] K.L. Killops, L. M. Campos, C. J. Hawker, J. Am. Chem. Soc., 2018, 130 5062-5064.

[48] A. Fraix, T. Le Gall, M. Berchel, C. Denis, P. Lehn, T. Montier, P.A Jaffrès, Org. Biomol. Chem., 2013, 11, 1650-1658.

[49] S.S. Le Corre, M. Berchel, H. Couthon-Gourvès, J.P. Haelters, P.A Jaffrès, Beilstein J. Org. Chem., 2014, 10, 1166-1196.

[50] H.J. Risselada, S.J. Marrink, Phys. Chem. Chem. Phys., 2009, 11, $2056-$ 2067

[51] a) C. Bottier, J. Géan, F. Artzner, B. Desbat, M. Pézolet, A. Renault, D. Marion, V. Vié, BBA Biomembrane, 2007, 1768, 1526-1540. b) C. Bourlieu, G. Paboeuf, S. Chever, S. Pezennec, J-F Cavalier, F Guyomarc'h, A Deglaire, S Bouhallab, D Dupont, F Carrière, V Vié, Colloids and Surfaces B: Biointerfaces, 2016, 143, 97-106.

[52] I.R. Cooke, M. Desemo, Biophys. J., 2006, 91, 487-495.

[53] B.R. Lentz, Chem.Phys.Lipids, 1993, 64, 99-116.

[54] S.C. Hyde, I.A. Pringle, S. Abdullah, A.E. Lawton, L.A. Davies, A Varathalingam A, G. Nunez-Alonso, A.M. Green, R.P. Bazzani, S.G. Sumner-Jones, M. Chan, H. Li, N.S. Yew, S.H. Cheng, A.C. Boyd, J.C Davies, U. Griesenbach, D.J. Porteous, D.N. Sheppard, F.M. Munkonge E.W. Alton, D.R. Gill, Nat. Biotechnol., 2008, 26, 549-51.

[55] M. Berchel, T. Le Gall, J.P. Haelters, P. Lehn, T. Montier, P.A. Jaffrès, Mol. Pharm., 2015, 12, 1902-1910. 